\title{
Planetary boundary layer height from CALIOP compared to radiosonde over China
}

\author{
Wanchun Zhang ${ }^{1}$, Jianping Guo ${ }^{1}$, Yucong Miao ${ }^{1,2}$, Huan Liu ${ }^{1}$, Yong Zhang ${ }^{3}$, Zhengqiang Li $^{4}$, and Panmao Zhai ${ }^{1}$ \\ ${ }^{1}$ State Key Laboratory of Severe Weather, Chinese Academy of Meteorological Sciences, Beijing, 100081, China \\ ${ }^{2}$ Department of Atmospheric and Oceanic Sciences, Peking University, Beijing, 100871, China \\ ${ }^{3}$ Meteorological Observation Centre, China Meteorological Administration, Beijing, 100081, China \\ ${ }^{4}$ State Environmental Protection Key Laboratory of Satellites Remote Sensing, Institute of Remote Sensing \\ and Digital Earth of Chinese Academy of Sciences, Beijing, 100101, China
}

Correspondence to: Jianping Guo (jpguocams@gmail.com) and Panmao Zhai (pmzhai@cma.gov.cn)

Received: 22 March 2016 - Published in Atmos. Chem. Phys. Discuss.: 6 April 2016

Revised: 17 June 2016 - Accepted: 8 July 2016 - Published: 8 August 2016

\begin{abstract}
Accurate estimation of planetary boundary layer height $(\mathrm{PBLH})$ is key to air quality prediction, weather forecast, and assessment of regional climate change. The PBLH retrieval from the Cloud-Aerosol Lidar with Orthogonal Polarization (CALIOP) is expected to complement groundbased measurements due to the broad spatial coverage of satellites. In this study, CALIOP PBLHs are derived from combination of Haar wavelet and maximum variance techniques, and are further validated against PBLHs estimated from ground-based lidar at Beijing and Jinhua. Correlation coefficients between PBLHs from ground- and satellitebased lidars are 0.59 at Beijing and 0.65 at Jinhua. Also, the PBLH climatology from CALIOP and radiosonde are compiled over China during the period from 2011 to 2014. Maximum CALIOP-derived PBLH can be seen in summer as compared to lower values in other seasons. Three matchup scenarios are proposed according to the position of each radiosonde site relative to its closest CALIPSO ground tracks. For each scenario, intercomparisons were performed between CALIOP- and radiosonde-derived PBLHs, and scenario 2 is found to be better than other scenarios using difference as the criteria. In early summer afternoon over $70 \%$ of the total radiosonde sites have PBLH values ranging from 1.6 to $2.0 \mathrm{~km}$. Overall, CALIOP-derived PBLHs are well consistent with radiosonde-derived PBLHs. To our knowledge, this study is the first intercomparison of PBLH on a large scale using the radiosonde network of China, shedding important light on the data quality of initial CALIOP-derived PBLH results.
\end{abstract}

\section{Introduction}

The planetary boundary layer (PBL), the lowest layer of the troposphere closest to the surface, is directly influenced by the presence of the Earth's surface and responds to surface forcings (e.g., sensible heat flux, mechanical drag) on a timescale of about an hour or less (Stull, 1988). Given the nonlinearity and complexity of convective and turbulent processes occurring within the PBL, the terrestrial PBL is extremely complex. The PBL processes play significant roles in modulating the exchange of momentum, heat, moisture, gases, and aerosols between the Earth's surface and the free troposphere (Hu et al., 2010, 2014; Miao et al., 2015). The variations of PBL height are found to be crucial for severe haze formation in urban environments (R. Zhang et al., 2015). Therefore, a growing consensus has been reached on the role boundary layer processes and structures have played in greatly advancing our capabilities in understanding and predicting weather, climate, and air quality (Medeiros et al., 2005; Hong et al., 2006; Zhang et al., 2007; Hu et al., 2010).

The PBL height (PBLH), which determines the vertical extent of turbulent mixing and convection activity within it, is a key length scale in weather, climate, and air quality models. The accurate representations of vertical diffusion, cloud formation/development, and pollutant deposition in numerical models largely rely on the reliable parameterization of the PBL (Hu et al., 2014; Seibert, 2000; Xie et al., 2012; Wang et al., 2013a, b). The large-scale PBLH observations in China facilitate our understanding of the PBL role in complex land- 
atmosphere interaction and thus in mitigating uncertainties in Earth system science and global sustainability issues, which is one of the main aims of the PEEX (Pan-Eurasian Experiment) program (Kulmala et al., 2015).

The PBLH typically varies from less than $100 \mathrm{~m}$ to several thousand meters (Hennemuth and Lammert, 2006). The most common PBLHs are derived from radiosonde soundings of temperature, humidity, and so on. The balloons are required to be launched twice daily for the purpose of operational weather forecast, or 4-8 times per day from the perspective of scientific research during intensive observation periods (Seibert, 2000; Liu and Liang, 2010). Although the radiosonde can provide height-resolved temperature and humidity profiles for accurate estimation of PBLH, which is independent of cloud cover conditions, it is still too sparse to detect the PBL evolution on a large spatial scale and thus cannot adequately serve the PBL research on global or even regional scales (Sawyer and Li, 2013). With the limited available radiosonde observations (mostly from the Unite States and Europe), Seidel et al. (2010, 2012) constructed a general picture of PBLH climatology on a global scale. However, they did not give much detailed information of the PBL over China, in part due to the lack of high-resolution observations in China. In 2011, a land-based radiosonde network across China was successfully deployed by the China Meteorological Administration (CMA), which provides a unique opportunity to fill in the existing gap.

In addition to the land-based radiosonde observations, the lidars profiling atmospheric aerosols or trace gases can be used to study PBL structure (Seibert, 2000). It is well known that aerosol concentrations vary significantly with height, which not only affects the detection of boundary layer but also becomes a large source of uncertainty particularly for satellite-based aerosol retrievals using ultraviolet (UV) wavelengths (e.g., Torres et al., 1998, 2013; Huang et al., 2015). For the measurements of active remote-sensing instruments, such as the Cloud-Aerosol Lidar with Orthogonal Polarization (CALIOP) aboard Cloud-Aerosol Lidar and Infrared Pathfinder Satellite Observations (CALIPSO) (Winker et al., 2007), aerosols can be detected and used as tracers of PBL dynamics. This is due to the fact that the number concentration of aerosol particles in the PBL is often greater than that in the free troposphere (Leventidou et al., 2013). More importantly, unlike a radiosonde measurement that only provides a "snapshot" of a PBL profile at a fixed site (Seibert et al., 2010), the spaceborne lidar can obtain PBL variations over a large area of interest, especially over remote regions (Jordan et al., 2010; W. Zhang et al., 2015).

The overpass time of CALIOP/CALIPSO is around 13:30 local time (LT), which is almost coincident with the atmospheric sounding observations around 14:00 Beijing Time (BJT) operated by CMA in summer. In the late morning and afternoon, when the convective boundary layer is well established, a strong gradient of aerosol particles can often be seen at the top of the convective boundary layer, and thus the lidar-detected PBLH is generally in good agreement with the radiosonde-derived PBLH (Garratt, 1994; Seibert, 2000; Hennemuth and Lammert, 2006). Therefore, at the time of CALIOP overpasses (13:30 LT), this method seems suitable to determine the convective boundary layer height.

As one of the initial attempts to validate the CALIOPderived PBLHs, Kim et al. (2008) carried out an intercomparison study between PBLHs from radiosondes and CALIOP measurements, showing high consistency between them. Similarly, Ho et al. (2015) compared the marine boundary layer heights from CALIOP profiles with those from radiosonde soundings. On the other hand, large biases of the seasonal and diurnal variations in PBLHs were observed, most likely due to the different methods utilized based on radiosonde, ground-based lidar, and CALIOP observations over one site in South Africa (Korhonen et al., 2014). Although CALIOP possesses the ability to derive PBLHs over large and remote regions on a regular basis, most previous comparison studies only involved one or a few sites. Therefore, a comprehensive evaluation of CALIOP-derived PBLH with large-scale land-based radiosonde observations remains lacking. In this study, the long-term CALIOP-derived PBLH over China will be validated and assessed by the measurements of the land-based radiosonde network of CMA.

From the climatological point of view, the PBLH retrieval from CALIOP is expected to complement the ground-based site measurements due to its large spatial coverage. The main objective of this study is twofold: (1) to construct a climatological CALIOP-derived PBLH data set and (2) to quantify the discrepancies between CALIOP-derived and radiosondederived PBLHs. The remainder of this paper proceeds as follows: the data and methods used are described in Sect. 2. Section 3 reports the comparison results of CALIOP-derived PBLH using ground-based lidar measurements. The spatial and temporal distribution pattern of CALIOP-derived PBLH is presented as well. Moreover, intercomparisons between PBLHs derived from CALIOP and radiosonde measurements will be performed. Lastly, a brief summary is given in Sect. 4 .

\section{Data and methods}

\subsection{Radiosonde observations and their processing}

The radiosonde measures once per second, acquiring detailed vertical profiles of temperature, pressure, relative humidity, wind speed, and wind direction over a given weather station. The sounding balloons are operationally launched twice a day at fixed times, i.e., 08:00 and 20:00 BJT. Figure 1 shows all the radiosonde sites. Fortunately, CMA required the soundings to be launched three to four times a day in summer (the wet season), i.e., 02:00, 08:00, 14:00, and 20:00 BJT to seamlessly monitor vertical structure of atmosphere, and thus to better serve high-impact weather forecasting (Guo et al., 2016). Owing to our focus on the convec- 
tive PBL in the daytime, the 14:00 BJT soundings in summer allow us to determine PBLHs over most weather sites throughout China, which are used for comparison analysis with CALIOP-derived PBLH, which is typically available at 13:30 LT.

As summarized in Seidel et al. (2010), there are seven commonly used methods to derive PBLHs based on the profiles of temperature, potential temperature, virtual potential temperature, relative humidity, specific humidity, and refractivity. The traditional approach described in the textbooks (e.g., Oke, 1988; Sorbjan, 1989; Garratt, 1992) typically defines PBLH as the pressure level where the maximum vertical gradient of potential temperature occurs, indicative of a transition from a convectively less stable region below to a more stable region above. Recently, a more sophisticated method was developed (Brooks, 2003; Davis et al., 2000), which involves the wavelet covariance transform. The algorithm of wavelet covariance transform was first proposed by Gamage and Hagelberg (1993) as a way to detect step changes in a signal.

By combining the methods of wavelet covariance and iterative curve fitting (Steyn et al., 2009), Sawyer and Li (2013) developed a novel algorithm (hereafter called SL2013) which can be applied to robustly derive PBLHs from both radiosonde and lidar measurements due to the fact that prior knowledge of instrument properties and atmospheric conditions has been adequately considered. The measurement time of radiosonde (around 14:00 BJT) generally corresponds to the time with the largest solar radiation received at the surface, which leads to the potential temperature profile more often than not exhibiting the typical structure of the convective BL. However, due to the potential uncertainties caused by the sensitivity of vertical resolution, and the wide range of sounding time (in LT) at different sites across China, SL2013 tends to exhibit advantages over the method of maximum potential temperature gradient. This is most likely because SL2013 is flexible and simple enough for automatic analyses of long-term sounding data at multiple sites and is able to compensate for noisy signals and low vertical resolution in the soundings. Therefore, SL2013 has been applied to extract PBLHs from radiosonde observations. Also note that the extreme convective weather system, which is a disturbing factor, will inevitably exert large uncertainties on the retrieved PBLH. For instance, as the deep convective cloud occurs the PBL will collapse, leading to an extremely large value. These cases will be excluded for further comparison analysis with CALIOP-derived PBLHs. The sounding observations of 113 radiosonde sites (black dots in Fig. 1) during the period 2011-2014 are then used to calculate PBLHs and to perform comparison analysis with the CALIOP-derived PBLHs as well.

\subsection{Ground-based lidar observations}

Ground-based lidar observations from two sites (i.e., Beijing and Jinhua) have been used to evaluate the PBLHs retrieved from CALIOP. The site of Beijing $\left(40.00^{\circ} \mathrm{N}, 116.38^{\circ} \mathrm{E}\right)$ is located on the campus of the Institute of Remote Sensing and Digital Earth, Chinese Academy of Sciences, where the CE370 micro-pulse lidar (made by CIMEL of France) was deployed during the period of 1 January 2014 to 31 December 2014. The profiles of aerosol backscatter coefficient obtained from CE370 have a vertical resolution of $15 \mathrm{~m}$. The laser transmitter system is reported to have a diameter of $20 \mathrm{~cm}$, which is used to expand laser beam through a refracting telescope.

The other ground-based lidar was deployed on the campus of Zhejiang Normal University at Jinhua $\left(29.0^{\circ} \mathrm{N}, 119.5^{\circ} \mathrm{E}\right)$, Zhejiang Province. The altitude of this site is $71 \mathrm{~m}$ above sea level. Jinhua, located in the Yangtze River Delta of eastern China, has undergone a deterioration of air quality due to the rapid economic development in recent years (Guo et al., 2011; Wang et al., 2015). The ground-based lidar is developed by the Anhui Institute of Optics and Fine Mechanics (AIOFM), Chinese Academy of Sciences (CAS), and deployed at Jinhua, which is similar to CALIOP with two orthogonally polarized channels at $532 \mathrm{~nm}$ and one channel at $1064 \mathrm{~nm}$. The algorithm developed by W. Zhang et al. (2015) has been applied to the profiles of ground-based lidars deployed at Beijing and Jinhua. More specifically, only the segment of CALIOP profiles within a circle of $75 \mathrm{~km}$ radius centered at the abovementioned two ground-based lidar sites is included in the PBLH retrievals. Due to the neighboring ground tracks of CALIPSO at an approximately $100-150 \mathrm{~km}$ longitudinal interval over China, a $75 \mathrm{~km}$ radius circle cantered at each ground-based lidar site has been determined for its matchup with CALIOP, as has been the matchup of radiosonde site with CALIOP.

The ground-based lidars are typically shut off during (1) maintenance period of lidar or (2) the time period when lidar cannot normally work, leading to unwanted gaps in lidar observations. Meanwhile, unfavorable weather conditions including rains, heavy haze episodes, etc. - generally lead to unreliable PBLH retrievals. Overall, the data volume fraction is roughly $87.7 \%$ for the Beijing site. The lidar measurements with PBLH detection differ largely by month. A total of $133 \mathrm{~h}$ was obtained in May, as compared with $661 \mathrm{~h}$ in March (Fig. S1 in Supplement). Given the unreliable PBLH retrievals under certain unfavorable conditions as described above, the annual average of the data is reduced to $64 \%$ at the Beijing site, which is similar to $72 \%$ at the Jinhua site.

\subsection{CALIOP observations and their processing}

The CALIOP aboard the CALIPSO platform (flying as part of the A-Train satellite constellation since April 2006) is a three-channel elastic backscatter lidar, which is optimized for 


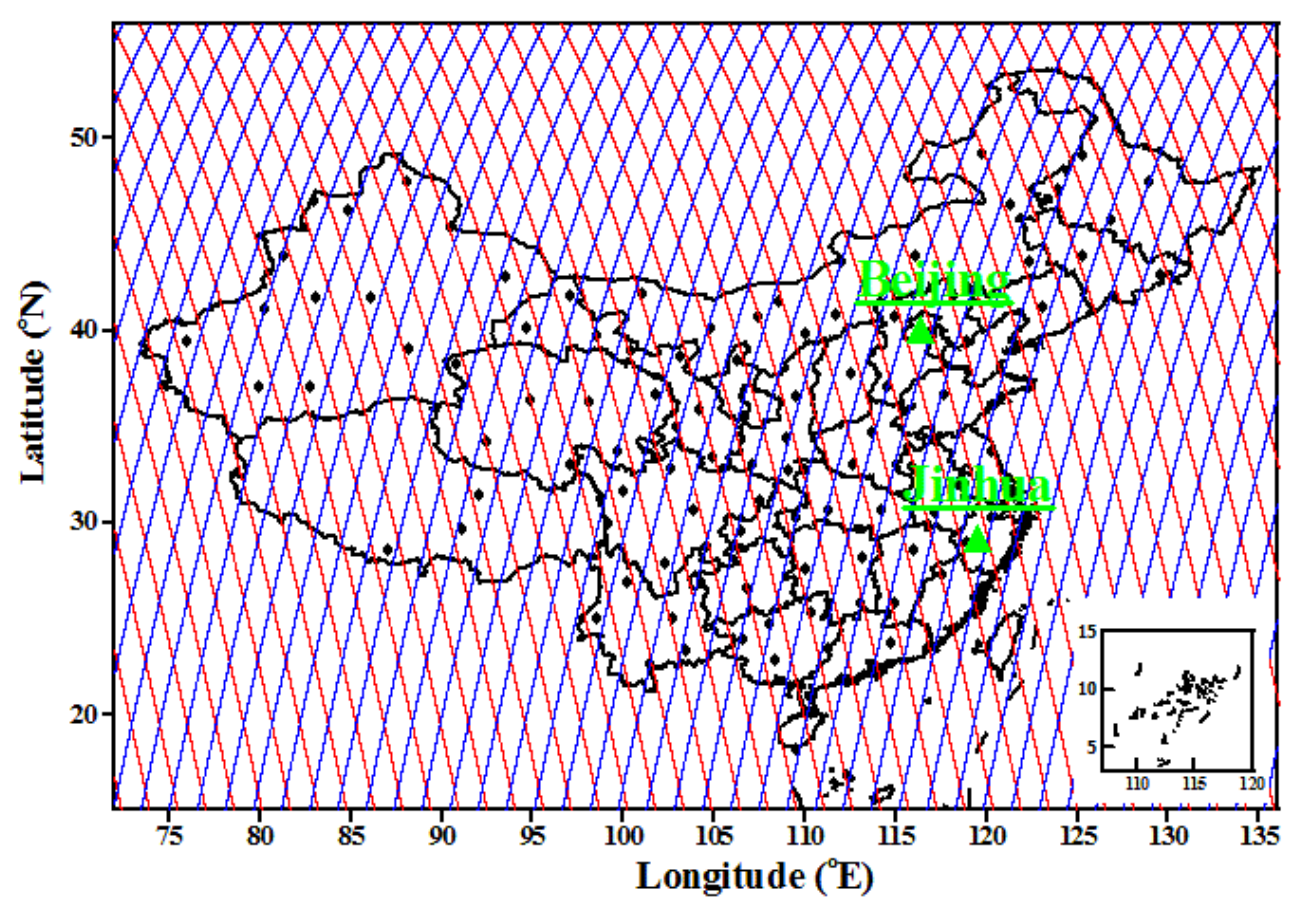

Figure 1. Geographic distribution of radiosonde sites and ground tracks for CALIPSO over China. Red lines represent the ground tracks for the CALIOP daytime orbits (in ascending mode), and blue lines for the CALIOP nighttime orbits (in descending mode). The black dots denote all radiosonde sites operated and maintained by the China Meteorological Administration. Beijing and Jinhua (green solid triangles) are two sites deployed with ground-based lidar.

aerosol and cloud profiling. It measures attenuated backscatter coefficients at a resolution of $1 / 3 \mathrm{~km}$ in the horizontal at the visible wavelength $(532 \mathrm{~nm})$ and near-infrared wavelength $(1064 \mathrm{~nm})$, and its vertical resolution varies with altitude as follows: $30 \mathrm{~m}$ from ground to $8.2 \mathrm{~km}, 60 \mathrm{~m}$ from 8.2 to $20.2 \mathrm{~km}$, and $180 \mathrm{~m}$ from 20.2 to $30.1 \mathrm{~km}$ (Winker et al., 2009; Huang et al., 2015). All satellites of the A-train constellation are flying on a $705 \mathrm{~km}$ altitude Sun-synchronous polar orbit covering the Earth from $82^{\circ} \mathrm{N}$ to $82^{\circ} \mathrm{S}$ with a 16 day repetition cycle, with a nominal ascending node Equatorcrossing time of 13:30 (01:30) local daytime (nighttime) (Liu et al., 2009; Winker et al., 2003, 2007). As shown in Fig. 1, red lines represent the ground tracks over China for the daytime overpasses of CALIPSO (in ascending mode), and blue lines indicate ground tracks for nighttime overpasses of CALIPSO (in descending mode). The neighboring ground track is at a longitudinal interval of approximately $150 \mathrm{~km}$, varying with latitudes.

The PBLH is predominantly estimated from the CALIOP Level 1 product - the total attenuated backscatter coefficient - in combination with the Level 2 product of cloud layer products (horizontal ground resolution is $1 / 3 \mathrm{~km}$ ) for cloud screening. Resembling the methods utilized to derive PBLHs proposed by Jordan et al. (2010), we rely on the maximum variance algorithm to derive PBLHs from CALIOPattenuated backscatter coefficient profiles at wavelengths of $532 \mathrm{~nm}$, in combination with the Haar wavelet technique.
The maximum variance algorithm originated from the ideas proposed by Melfi et al. (1985) and heavily relies on the existence of a strong aerosols concentration gradient at the top of the PBL, which corresponds to the level where lidar backscatter shows the maximum standard deviations. This method has been widely used to derive PBLHs from CALIOP so that the global seasonal variations can be inferred (McGrath-Spangler and Denning, 2012, 2013). However, either maximum variance algorithm or Haar wavelet technique has its weakness due to the strong dependency on the chosen strategy in the threshold values. To make sure the comparison between radiosonde-derived PBLHs and CALIOP-derived ones are reliable and robust, the combined algorithm has been applied on the matched-up CALIOP profiles (scheme described in Sect. 2.2). All the comparisons are limited to daytime measurements due to the nature of the convective boundary layer, unless noted otherwise.

Due to the most likely blocking and attenuation caused by optically thin or thick clouds, we performed cloud-screen procedures prior to the algorithm mentioned above applied to the CALIPSO Level 1 profile data. The CALIPSO measurements were retained for PBLH retrievals at grid points where the number of valid (i.e., without cloud) CALIPSO overpasses exceeded $15 \%$ of the total number of overpasses. As such, we can minimize the effect of clouds on the retrieved PBLHs to a certain degree. Meanwhile, to improve the signal-to-noise ratio (SNR) for better PBLH retrievals, 
roughly 15 CALIOP profiles with $333 \mathrm{~m}$ resolution along track were resampled to one $5 \mathrm{~km}$ resolution profile for all CALIOP observations.

As a good case in point for a better view of the results derived using the above algorithms, the CALIOP-derived PBLHs (indicated by the black line) on 15 January 2011 over southeastern China are shown in Fig. 2. By visual interpretation, we can see that the derived-PBL tops are just located at the levels where aerosol backscatter signals change abruptly.

\section{Results and discussion}

\subsection{Comparison of CALIOP-derived PBLH against ground-based lidar-derived PBLH}

In order to make reliable comparison between CALIOP- and radiosonde-derived PBLHs, the former data will undergo an evaluation using ground-based lidar, which typically shares the similar techniques. To minimize the influence of cloud on the PBLH determination, all the lidar measurements at Beijing and Jinhua with clouds (extracted directly from the meteorological data at a neighboring weather station) have been excluded for further analyses.

The scatterplots are shown in Fig. 3 concerning the comparison between the ground-based lidar-derived PBLHs and CALIOP-derived PBLHs at Jinhua and Beijing $\left(40.0^{\circ} \mathrm{N}\right.$, $116.4^{\circ} \mathrm{E}$ ). Due to the twice-per-month revisit period of the CALIPSO satellite, only 17 cases out of 24 at Beijing are selected, in which both CALIOP and ground-based lidar have matched up measurements at 13:30 LT. And the simultaneous PBLH retrievals have been carried out for 7 cases out of 12 at Jinhua. For the overall comparison between the PBLHs derived from ground-based lidar and CALIOP, the correlation coefficient through orthogonal regression reaches 0.59 at Beijing and 0.65 at Jinhua. Due to the limited sample size, quality of the CALIOP-derived PBLHs is still under investigation. We will perform further evaluations as long as more ground-based lidar observations are available. Regardless of all these concerns, correlation coefficients obtained here are similar to those reported at the Semi-Arid Climate and Environment Observatory of Lanzhou University (SACOL) site of northwestern China (e.g., Liu et al., 2015).

\subsection{CALIOP-derived PBLH climatology throughout China}

Figure 4 presents the spatial distributions of seasonal mean PBLHs with $0.2^{\circ} \times 0.2^{\circ}$ resolution derived from CALIPSO afternoon measurements during the period 2011 through 2014. The original $5 \mathrm{~km}$ PBLH data have been smoothed and resampled to $20 \mathrm{~km}$ resolution to highlight the coherent large-scale structures. It can be clearly seen that the PBLHs over China exhibit large spatial and seasonal variations. On average, both Fig. 4 and Table 1 indicate that the highest PBLHs $(1.82 \mathrm{~km} \pm 0.31 \mathrm{~km})$ were seen in summer (June,
Table 1. Statistics of the CALIOP-derived PBLH in different seasons during the period 2011-2014. The mean PBLHs for all the grids are first calculated in China; then the maximum and minimum values of PBLHs are determined by sorting all the mean values. Meanwhile, the mean and standard deviation values of PBLH are determined as the average of mean values at every grid in China.

\begin{tabular}{lrrrr}
\hline & Spring & Summer & Autumn & Winter \\
\hline Maximum PBLH $(\mathrm{km})$ & 4.57 & 4.40 & 3.60 & 6.13 \\
Minimum PBLH $(\mathrm{km})$ & 0.15 & 0.38 & 0.22 & 0.21 \\
Mean PBLH $(\mathrm{km})$ & 1.72 & 1.82 & 1.56 & 1.51 \\
Standard deviation & 0.35 & 0.31 & 0.30 & 0.40 \\
of PBLH $(\mathrm{km})$ & & & & \\
\hline
\end{tabular}

July and August), mainly ranging from 1.5 to $2.5 \mathrm{~km}$. On the other hand, the lowest PBLH values $(1.51 \mathrm{~km} \pm 0.40 \mathrm{~km})$ occur in winter (December, January, and February), when the development of PBL is typically suppressed due to the smaller amount of solar radiation received at the surface. In contrast, the more intense solar radiation reaching the surface in summer favors the PBL development (Stull et al., 1988). As shown in Table 1, the maximum PBLHs can reach up to 5-6 km, especially in winter (due to the prevalent large wind). Therefore, we set the CALIOP-retrieved PBLHs to be within 0.25 and $3 \mathrm{~km}$, which is a reasonable height range for the midday PBL, highly consistent with the processing methods by McGrath-Spangler (2012). Statistics showed that only $2.1 \%$ of all data have PBLH higher than $3 \mathrm{~km}$ and $8.8 \%$ lower than $0.25 \mathrm{~km}$, which have been excluded for further analyses.

In terms of the discrepancy in spatial distribution of PBLH, the Tibetan Plateau (TP) was characterized by high values, irrespective of the evolution of seasons. Over eastern China, particularly the regions with large population and severe air pollution (Guo et al., 2009, 2011) (e.g., North China Plain, the Yangtze River Delta, and Pearl River Delta), the PBLHs were higher in spring and summer but did not show the expected large seasonal variation. During the seasons (such as winter) when haze events occur frequently, due to the suppression by aerosol radiative effects and aerosolwind interactions (Xia et al., 2007; Yang et al., 2016), relatively shallow PBLHs can apparently be seen across most of China, in good agreement with previous findings (e.g., Quan et al., 2013; Gao et al., 2015; Miao et al, 2016). This aerosolrich haze, in combination with lowered PBL, tends to significantly delay precipitation, suppressing or enhancing its peak intensity (Wang et al., 2011; Guo et al., 2016). The spatial distribution of PBLH revealed a tendency for higher PBLH over high-elevation regions, consistent with dependence on elevation reported in the United States (Seidel et al., 2012). Such spatial variation of PBLH may be related to the local land surface and hydrological processes (Seidel et al., 2012). 


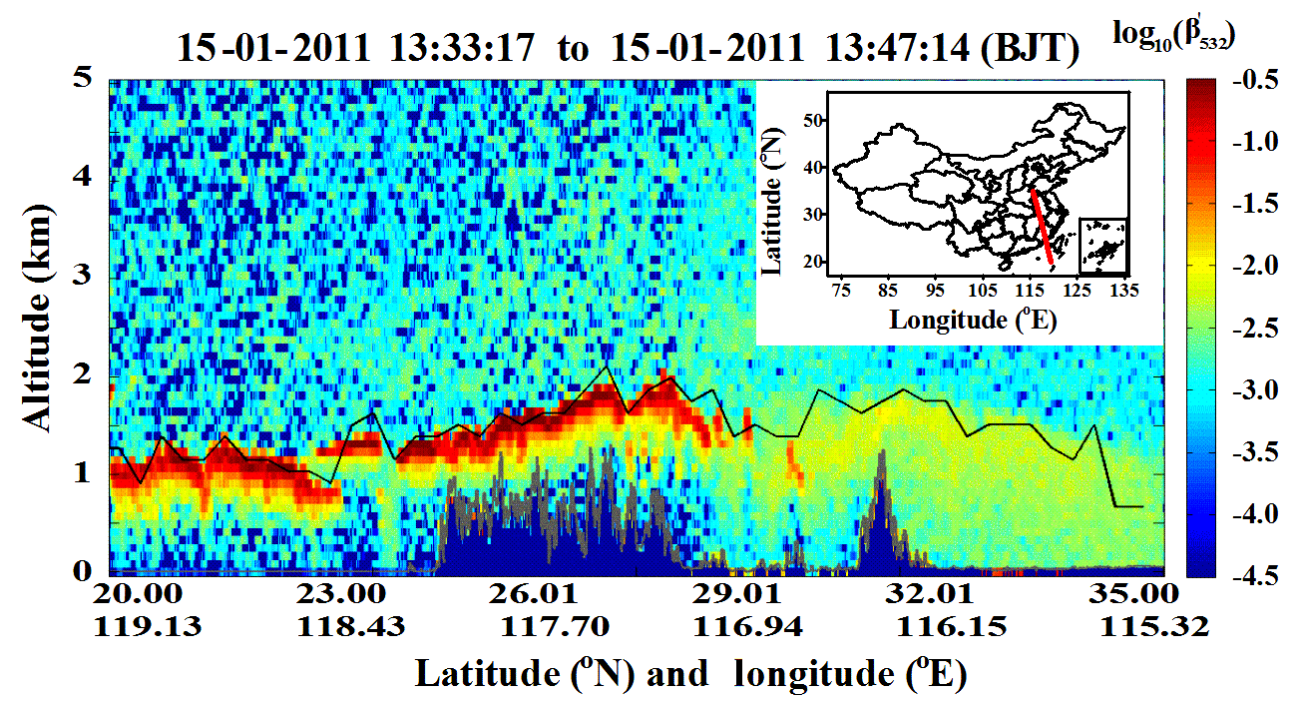

Figure 2. Curtain plot of attenuated backscatter coefficient as observed from CALIOP aboard CALIPSO on 15 January 2011 . The black line indicates the derived PBLH (above ground level), and the grey line immediately on top of the blue region represents the terrain surface (directly extracted from CALIOP data). The red line in the inlet map corresponds to the ground track of CALIOP/CALIPSO over southeastern China.

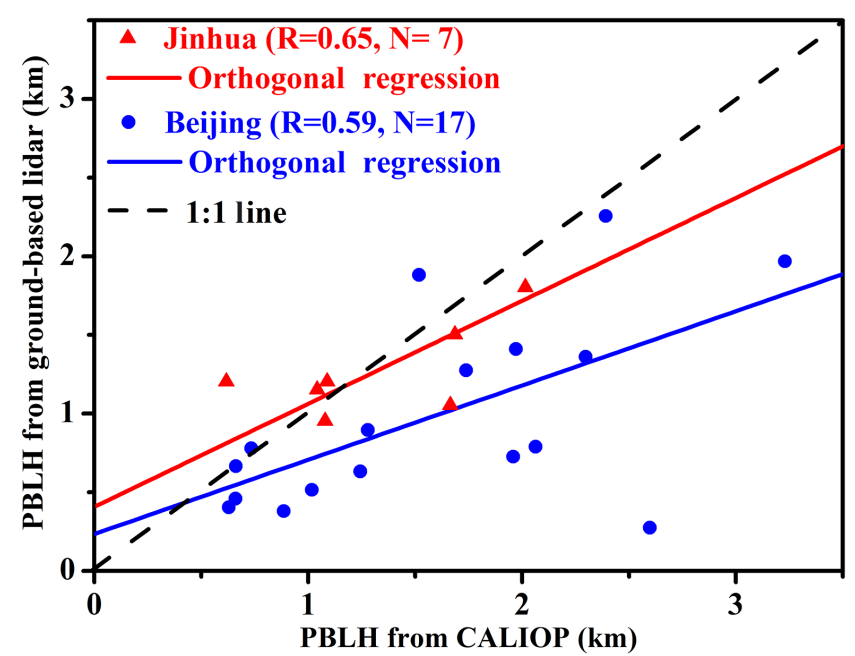

Figure 3. Scatterplot for comparing PBLHs from CALIOP to those from ground-based lidars at Beijing (blue dots) during the period 1 January 2014 to 31 December 2014 and Jinhua (red triangles) during the period of 1 June 2013 to 31 December 2013. Blue and red lines denote the linear fit to the data at Beijing and Jinhua sites, respectively, and the black dashed line the $1: 1$ correlation. The number of collocated data samples and corresponding correlation coefficient $(R)$ are shown as well.

\subsection{Matchup between CALIOP profiles and radiosonde soundings}

As revealed in Sect. 2.3, we have averaged out the PBLHs derived from the CALIOP profiles, which are then involved in comparison analysis with the mean PBLHs from radiosonde soundings. After multiple rounds of iteration through the positions of each radiosonde site over China relative to its closest CALIPSO ground tracks, a total of three scenarios are representative of all the cases, as shown in Fig. 5. Scenario 1 denotes the cases with two CALIOP ground tracks, the shortest distance to which each is more than $37.5 \mathrm{~km}$ from each radiosonde site. In contrast, scenario 2 represents the cases with one CALIOP ground track, the shortest distance to which is less than $37.5 \mathrm{~km}$ from each radiosonde site. Scenario 3 is the same as scenario 2 except that the shortest distance to the CALIOP ground track is more than $37.5 \mathrm{~km}$ from radiosonde site.

The details of the classification criteria are summarized in Table 2. Out of the total of 113 radiosonde sites, 64 sites belonged to scenario 2 . That means about $56.6 \%$ of all radiosonde sites make a good match with CALIOP profiles for their nearest distance to CALIPSO ground tracks, less than $37.5 \mathrm{~km}$. In comparison, there are 22 sites $(19.5 \%)$ attributed to scenario 1 , whereas 27 sites $(23.9 \%)$ are attributed to scenario 3.

Figure 6 shows the geographic distribution concerning the location of each radiosonde site relative to its closest CALIOP ground tracks inside a circle of radius $75 \mathrm{~km}$ over China, which are stratified by scenarios 1,2 , and 3. Owing to the nearest distance to radiosonde site in scenario 2, profiles in CALIOP observations can be used to better capture the PBL evolution and thus facilitate the intercomparisons. It happens that the radiosonde sites $(56.6 \%)$ belonging to scenario 2 are uniformly distributed over China, indicating that most of the radiosonde sites in China can be collocated well with afternoon CALIPSO overpass. 

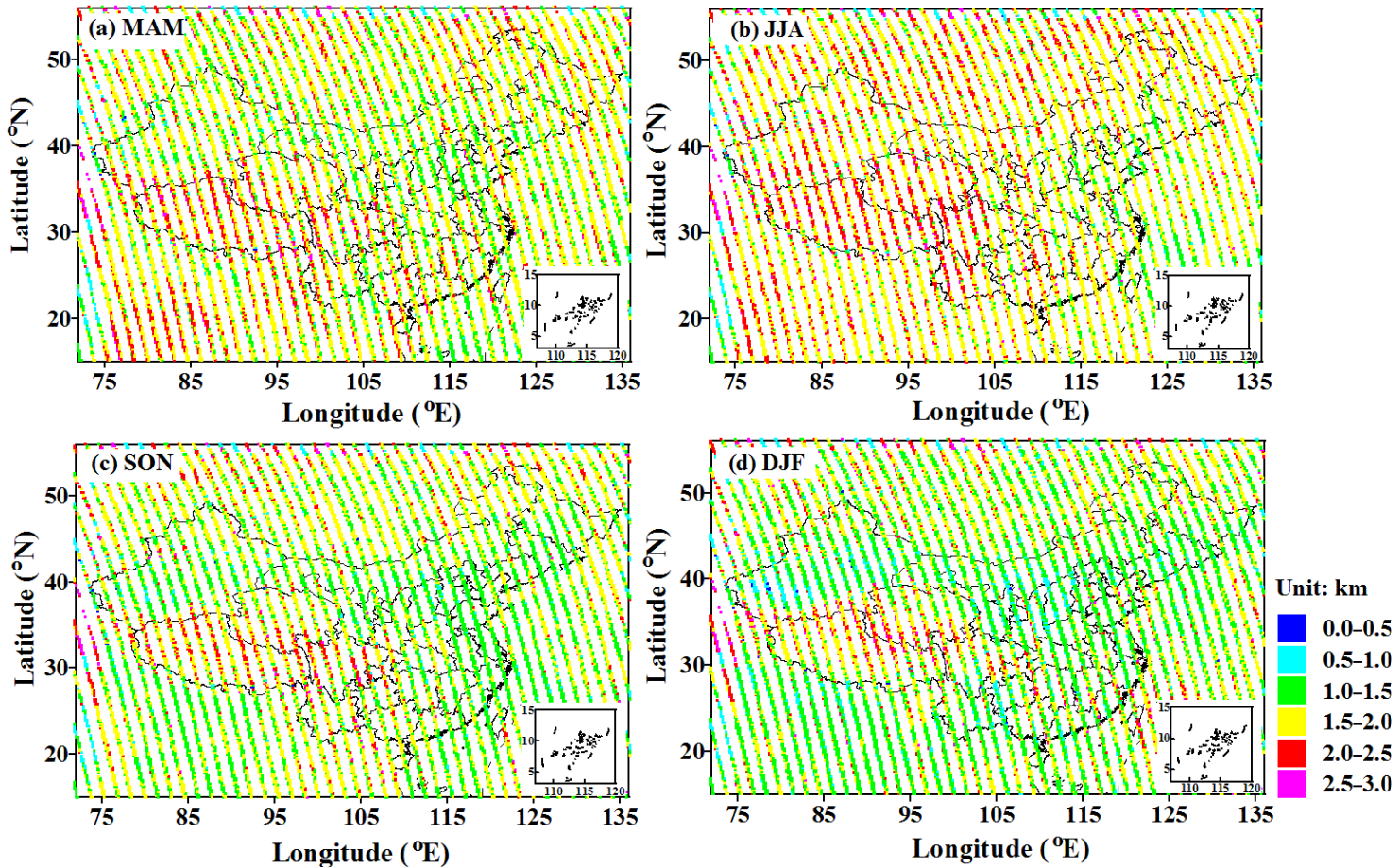

Figure 4. Spatial distributions of climatological PBLHs derived from CALIOP at 13:30 BJT in (a) spring (March-April-May, MAM), (b) summer (June-July-August, JJA), (c) autumn (September-October-November, SON), and (d) winter (December-January-February, DJF) during the period 2011-2014. Horizontal resolution is resampled to $20 \mathrm{~km}$ along the ground track.

(a) Scenario 1

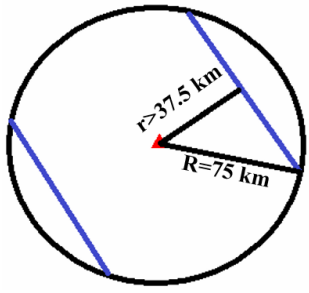

(b) Scenario 2

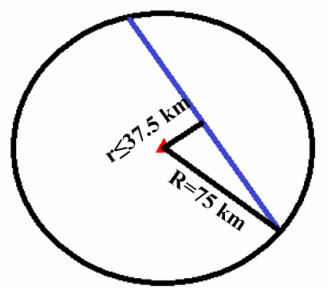

(c) Scenario 3

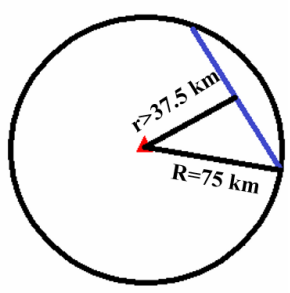

Figure 5. Schematic diagrams showing the location of CALIOP ground tracks relative to radiosonde sites according to (a) scenario 1 (with two CALIOP ground tracks, the shortest distance to each of which is more than $37.5 \mathrm{~km}$ from radiosonde site); (b) scenario 2 (with one CALIOP ground track, the shortest distance to which is less than $37.5 \mathrm{~km}$ from the radiosonde site); and (c) scenario 3 (with one CALIOP ground track, the shortest distance to which is more than $37.5 \mathrm{~km}$ from radiosonde site) showing the geometric relationship of CALIOP ground tracks relative to radiosonde sites. A circle with a radius of $75 \mathrm{~km}$ centered at radiosonde sites was chosen to obtain averaged PBLH from CALIOP, as compared with the measured PBLH from ground-based soundings.

Interestingly, most of the radiosonde sites in scenario 1 are located in northern China, as opposed to those in scenarios 3 in southern China. The more northward the radiosonde sites, the greater the number of the CALIPSO overpasses over the same circle of $75 \mathrm{~km}$ radius. Therefore, the distinct discrepancy in geographic distributions of radiosonde sites belonging to scenarios 1 and 3 is most likely due to latitude differences. More importantly, because the region of interest (China) spans several time zones, the spatial variations of radiosonde-derived PBLHs observed at fixed observation times $(14: 00 \mathrm{BJT})$ tend to be conflated with diurnal variations, as discussed in Sect. 4 below.

\subsection{Intercomparison between CALIOP- and radiosonde-derived PBLHs}

Using the algorithms detailed in Sect. 2, the PBLHs at all the 113 radiosonde sites have been successfully derived from radiosonde and CALIOP. In terms of the spatial differences of PBLHs, both CALIOP retrievals (Fig. 4b) and radiosonde observations (Fig. S2) show that large PBLH val- 


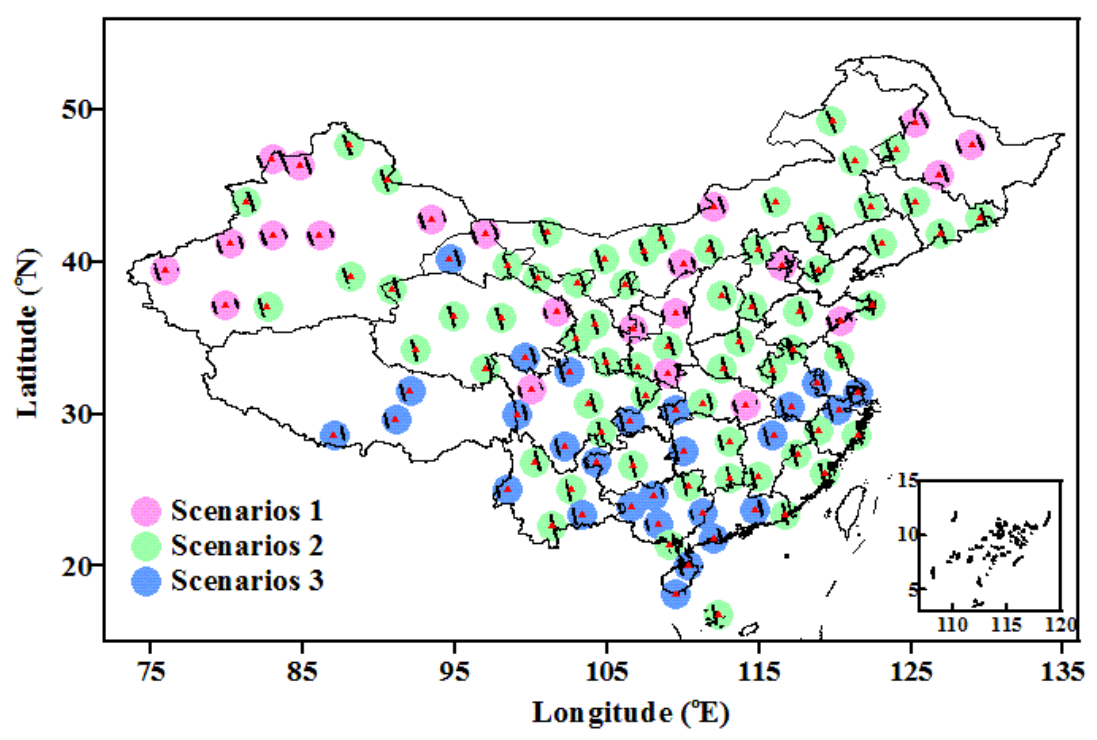

Figure 6. The geographic distribution map showing the location of radiosonde sites relative to CALIOP ground tracks over China. The red triangles denote the radiosonde sites, and the black lines show CALIOP tracks chosen for comparison analysis. The solid circles in cyan, green, and blue correspond to scenarios 1, 2, and 3 as defined in Fig. 5.

Table 2. Detailed descriptions with regard to the classification criteria of the scenario of the positions of the radiosonde site relative to the closest CALIOP profiles, including the number of CALIPSO ground tracks for each scenario, the shortest distance (SD) to ground tracks, the total number of sites for each scenario in China, and the number of sites with overestimated averaged PBLHs (OE) or underestimated averaged PBLHs (UE) from CALIOP compared with radiosonde.

\begin{tabular}{rrrrrr}
\hline Scenario & $\begin{array}{r}\text { No. of CALIPSO } \\
\text { ground tracks }\end{array}$ & $\begin{array}{r}\text { SD } \\
(\mathrm{km})\end{array}$ & $\begin{array}{r}\text { No. of } \\
\text { sites }\end{array}$ & $\begin{array}{r}\text { No. of sites } \\
\text { with OE }\end{array}$ & $\begin{array}{r}\text { No. of sites } \\
\text { with UE }\end{array}$ \\
\hline 1 & 2 & $37.5<D \leq 75$ & 22 & 11 & 11 \\
2 & 1 & $0 \leq D \leq 37.5$ & 64 & 18 & 46 \\
3 & 1 & $37.5<D \leq 75$ & 27 & 7 & 20 \\
\hline
\end{tabular}

ues tend to occur on the Tibetan Plateau, in southwestern China, and in northern China in early summertime afternoon. This is indicative of good agreement between CALIOPand radiosonde-derived PBLH retrievals. Furthermore, the differences of PBLHs at every radiosonde site (Fig. 1) from CALIOP measurements at 13:30 LT minus those from radiosonde observations at 14:00 BJT in the summertime (June-July-August) during the period of 2011-2014 are calculated. Meanwhile, the differences of PBLHs are averaged out for each radiosonde site again according to three matchup scenarios for both CALIOP profiles and radiosonde sites described in Table 2.

As shown in Fig. 7a, the PBLH differences over most of the radiosonde sites to the east of $110^{\circ} \mathrm{E}$ longitude exhibit negative values, indicating CALIOP-derived PBLHs tend to be underestimated compared with radiosonde-derived PBLHs. In contrast, it is a different story (to be overesti- mated as compared with radiosonde) for the sites to the west of $110^{\circ} \mathrm{E}$ longitude (western China), especially in provinces such as Xinjiang, Sichuan, and Chongqing. The CALIOP observations at roughly 13:30 LT in western China have been compared with the radiosonde measurements at 14:00 BJT, which corresponds to 11:00-14:00 LT, differing by longitudes. Therefore, the relatively low PBLHs from the radiosondes in western China are expected to be in association with weak convection. This in turn leads to overestimated CALIOP-derived PBLHs in western China. However, there are other aspects neglected to be discussed here, which are beyond the scope of the paper.

All sites in Fig. 7a are divided into three subgroups according to the matchup scenario described in previous sections. Overall, the radiosonde-derived PBLHs tend to be overestimated compared with CALIOP-derived PBLHs due to the majority of radiosonde sites (77 of 113 sites, i.e., $68 \%$ ) showing lower PBLH values. This is also consistent with the results shown in Table 2. As shown in Fig. 7b-d, the average biases between CALIOP- and radiosonde-derived PBLHs for scenario 2 , as expected, have smaller magnitude $(0.17 \mathrm{~km})$, as compared with scenario 1 (with a magnitude of $0.22 \mathrm{~km}$ ). On the other hand, the smallest average bias $(0.15 \mathrm{~km})$ is observed for scenario 3. More statistics with regard to the biases between CALIOP- and radiosonde-derived PBLHs are illustrated in Fig. 8.

As indicated in Fig. 8, scenario 2 witnesses the least difference of $0.08 \mathrm{~km}$ between the CALIOP- and radiosondemedian PBLH values in contrast to larger differences of 0.24 and $0.12 \mathrm{~km}$ for scenarios 1 and 3 , respectively. In addition, the PBLH differences in terms of 25th- and 75th-percentile 

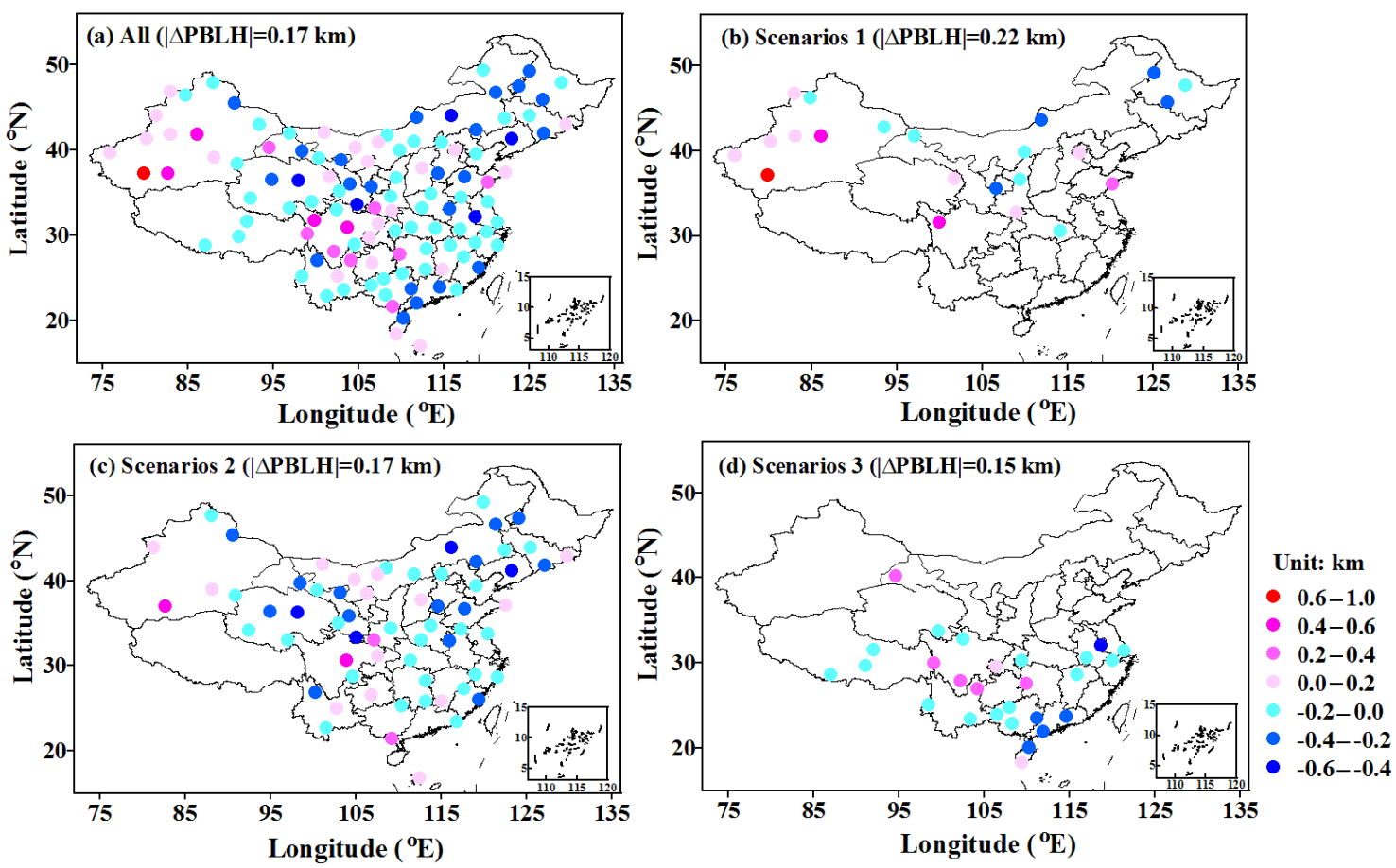

Figure 7. The geographic distribution map concerning the absolute difference of PBLH derived from CALIOP at 13:30LT minus that derived from radiosonde observations at 14:00 BJT in the summertime (June-July-August) during the period of 2011-2014. The differences of PBLHs are shown for all radiosonde sites in China (a) and for the radiosonde sites belonging to scenario 1 (b), scenario 2 (c), and scenario $3(\mathbf{d})$.

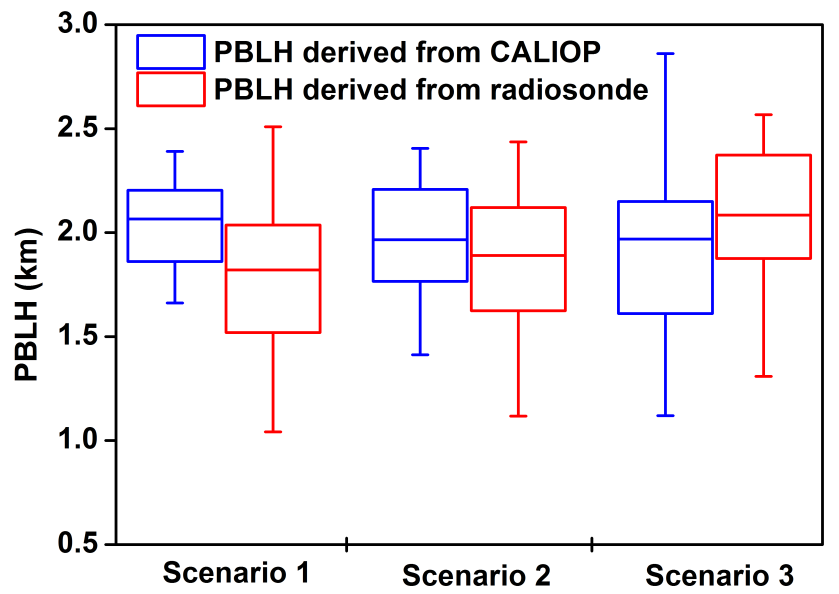

Figure 8. Box-and-whisker plot showing the 5th, 25th, 50th, 75th, and 95th percentile values of PBLH derived from CALIOP (in blue) and radiosonde (in red) for each scenario. Note that only 14:00 BJT radiosonde are used to make comparison with afternoon CALIOPderived PBLHs.

values for scenario 2 are much more indiscernible, as compared with those for other two scenarios. This implies that scenario 2 gains more advantages over the other two scenarios due to the smaller difference between CALIOP- and radiosonde-derived PBLHs.
Figure 9 shows the frequency for the number of radiosonde sites which are stratified by binned radiosonde-derived mean PBLHs (14:00 BJT) and CALIOP-derived mean PBLHs (around 13:30LT) over China in the summertime (JuneJuly-August) during the period of 2011-2014. Generally speaking, the PBLHs in early summer afternoon over China range from 1.6 to $2.0 \mathrm{~km}$, accounting for over $70 \%$ of the total radiosonde sites. The pattern in Fig. $9 \mathrm{c}$ is similar to that in Fig. 9a, suggesting that the results from scenario 2 are representative of the overall results over all sites. In other words, comparison of the histogram of CALIOP PBLHs to the radiosonde observations indicates that they are in good enough agreement with each other.

\section{Conclusions}

This study presents initial validation results of PBLHs from spaceborne CALIOP measurements by comparing coincidental observations from two ground-based lidars at Beijing from 1 January 2014 to 31 December 2014 and Jinhua from 1 June 2013 to 31 December 2013. Results show that the correlation coefficients between the two types of measurements are 0.59 at Beijing and 0.65 at Jinhua. The selected data set represents two different underlying land surfaces, i.e., urban and mountain area, both of which are obtained under cloudfree conditions. 

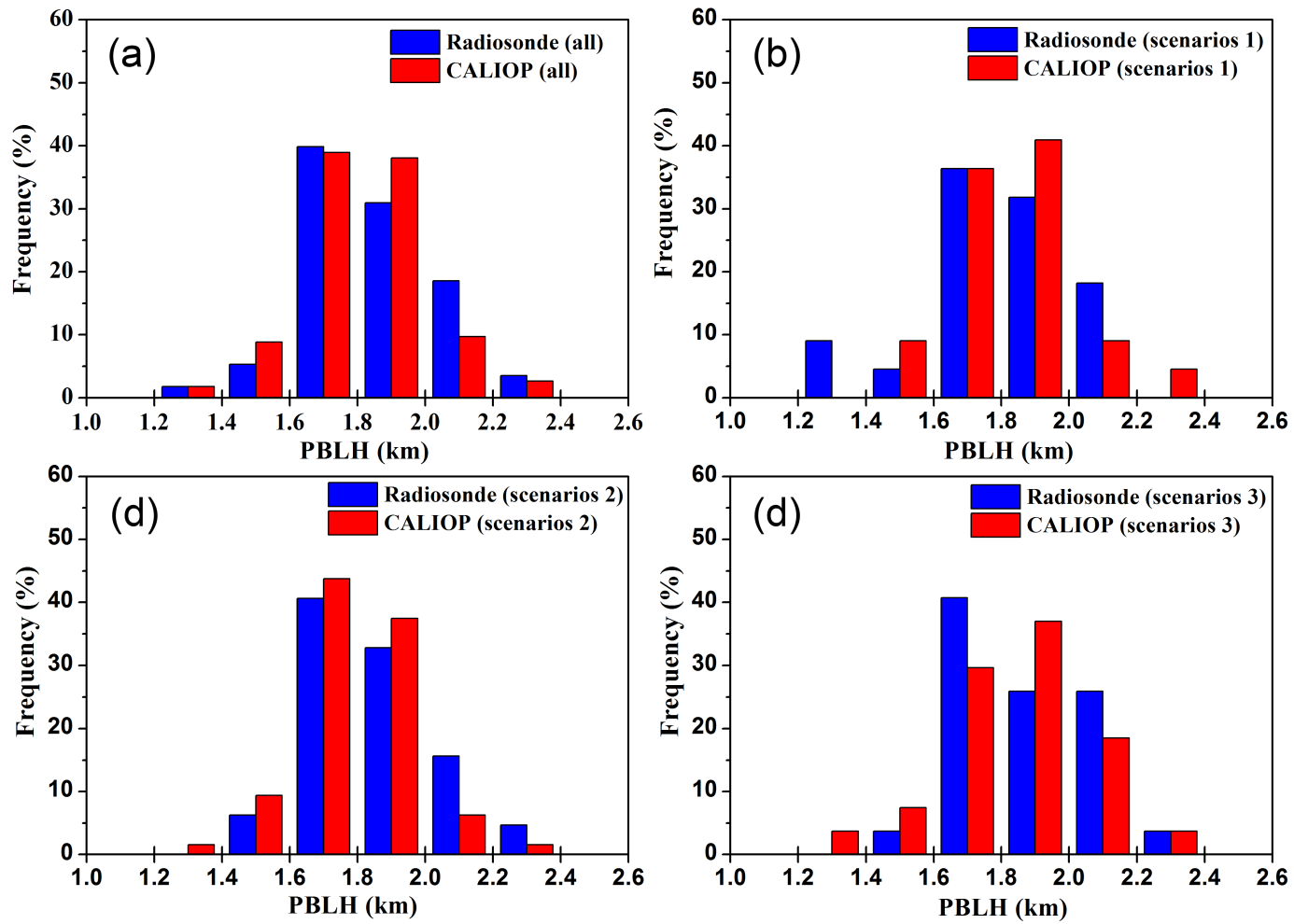

Figure 9. Histogram of the number of radiosonde sites stratified by binned radiosonde-derived mean PBLHs (blue bars, 14:00 BJT) and CALIOP-derived mean PBLHs (red bar, around 13:30 LT) over China in the summertime (June-July-August) during the period of 20112014 for all radiosonde sites (a) and for the radiosonde sites belonging to scenario 1 (b), scenario 2 (c), and scenario 3 (d). The frequency is calculated as the ratio of the number of radiosonde site in each PBLH bin to the total number of radiosonde sites. Note that the statistic results are only limited to the samples with collocated CALIOP- and radiosonde-derived PBLHs.

The climatology of seasonal mean PBLHs at $0.2^{\circ} \times 0.2^{\circ}$ resolution has been constructed, as derived from afternoon CALIPSO measurements during the period 2011 through 2014. The PBLHs over China are found to exhibit large spatial and seasonal variations. Overall, the summer season (June, July, and August) tends to have the highest PBLH values, in contrast with the lowest PBLH values occurring in winter (December, January, and February). Such seasonal variations of PBLH may be caused by the seasonal variation of solar radiation.

Prior to the comparison analysis between CALIOP- and radiosonde-derived PBLHs, three matchup scenarios are proposed according to the position of each radiosonde site over China relative to its closest CALIPSO ground tracks. The matchup of each radiosonde site with its neighboring CALIPSO ground tracks can be attributed to one the three scenarios. The spatial distribution of radiosonde sites belonging to scenario 2 indicates that most of the radiosonde sites in China can be collocated very well with afternoon CALIPSO overpass. Further comparative analyses suggest that CALIOP observations belonging to scenario 2 are better than radiosonde-derived PBLH, in terms of much smaller difference between radiosonde- and CALIOP-derived PBLHs.
Overall, CALIOP-derived PBLHs tend to be underestimated compared with radiosonde-derived PBLHs, which can be considered as a benchmark. On the other hand, more than $70 \%$ of the radiosonde sites across China in early summer afternoon have relatively higher PBLH values, which vary from 1.6 to $2.0 \mathrm{~km}$. Therefore, CALIOP PBLHs agree well with radiosonde-derived PBLHs. Despite the limitation in the presence of clouds, CALIOP has been routinely available for determination of PBLHs and is a valuable data source for long-term climatology analyses. To our knowledge, this study serves as the first intercomparison study of PBLHs between CALIOP- and radiosonde-derived PBLHs on a large scale using the radiosonde network of China. More detailed regional analyses have not been dealt with in this paper, which merit further investigation.

\section{Data availability}

CALIOP level 2 data can be downloaded via http://reverb.echo.nasa.gov/reverb/. The ECMWF reanalysis can be accessible via http://apps.ecmwf.int/datasets/data/ interim-full-daily/levtype $=\mathrm{sfc} /$. The PBLH data retrieved 
from radiosonde and CALIOP in this paper can be accessible upon request at email: jpguocams@gmail.com (J. Guo).

\section{The Supplement related to this article is available online at doi:10.5194/acp-16-9951-2016-supplement.}

Acknowledgements. This study was financially supported by the National Natural Science Foundation of China (grant no. 91544217), Ministry of Science and Technology of China (grant no. 2014BAC16B01), Natural Science Foundation of China (grant no. 41471301), Chinese Academy of Meteorological Sciences (grant no. 2014R18), and the Strategic Priority Research Program - Climate Change: Carbon Budget and Relevant Issues of the Chinese Academy of Sciences (XDA05100202). The authors would like to acknowledge CMA for providing the radiosonde data set for us to use. Special thanks go to NASA for making the CALIOP products accessible for public use; the Anhui Institute of Optics and Fine Mechanics (AIOFM) of the Chinese Academy of Sciences (CAS); the Institute of Remote Sensing and Digital Earth of Chinese Academy of Sciences of CAS; and Zhejiang Normal University for providing the ground-based lidar data.

Edited by: A. Ding

Reviewed by: two anonymous referees

\section{References}

Brooks, I. M.: Finding boundary layer top: Application of a wavelet covariance transform to lidar backscatter profiles, J. Atmos. Oceanic Tech., 20, 1092-1105, 2003.

Davis, K.J., Gamage, N., Hagelberg, C., Kiemle, C., Lenschow, D., and Sullivan, P.: An objective method for deriving atmospheric structure from airborne lidar observations, J. Atmos. Oceanic Tech., 17, 1455-1468, 2000.

Gao, Y., Zhang, M., Liu, Z., Wang, L., Wang, P., Xia, X., Tao, M., and Zhu, L.: Modeling the feedback between aerosol and meteorological variables in the atmospheric boundary layer during a severe fog-haze event over the North China Plain, Atmos. Chem. Phys., 15, 4279-4295, doi:10.5194/acp-15-4279-2015, 2015.

Gamage, N. and Hagelberg, C.: Detection and analysis of microfronts and associated coherent events using localized transforms, J. Atmos. Sci., 50, 750-756, 1993.

Garratt, J. R.: The Atmospheric Boundary Layer, Cambridge Atmospheric and Space Science Series, Cambridge Univ. Press, 335 pp., 1992.

Guo, J.-P., Zhang, X.-Y., Che, H.-Z., Gong, S. L., An, X. Q., Cao, C. X., Guang, J., Zhang, H., Wang, Y. Q., Zhang, X. C., Xue, M., and Li, X. W.: Correlation between PM concentrations and aerosol optical depth in eastern China, Atmos. Environ., 43, 5876-5886, 2009.

Guo, J.-P., Zhang, X., Wu, Y. R., Zhaxi, Y., Che, H., La, B., Wang, W., and Li, X.: Spatio-temporal variation trends of satellite-based aerosol optical depth in China during 1980-2008, Atmos. Environ., 45, 6802-6811, 2011.
Guo, J.-P., Deng, M. J., Lee, S.-S., Wang, F., Li, Z., Zhai, P. M., Liu, H., Lv, W. T., Yao, W., and Li, X.: Delaying precipitation and lightning by air pollution over Pearl River Delta, Part I: observational analyses, J. Geophy. Res.-Atmos., 121, 6472-6488, doi:10.1002/2015JD023257, 2016a.

Guo, J., Miao, Y., Zhang, Y., Liu, H., Li, Z., Zhang, W., He, J., Lou, M., Yan, Y., Bian, L., and Zhai, P.: The climatology of planetary boundary layer height in China derived from radiosonde and reanalysis data, Atmos. Chem. Phys. Discuss., doi:10.5194/acp2016-564, 2016b.

Hu, X. M., Nielsen-Gammon, J. W., and Zhang, F.: Evaluation of three planetary boundary layer schemes in the WRF model, J. Appl. Meteorol. Clim., 49, 1831-1844, 2010.

Hu, X. M., Ma, Z., Lin, W., Zhang, H., Hu, J., Wang, Y., Xu, X., Fuentes, J. D., and Xue, M.: Impact of the Loess Plateau on the atmospheric boundary layer structure and air quality in the North China Plain?: A case study, Sci. Total Environ., 499, 228-237, 2014.

Huang, J., Guo, J., Wang, F., Liu, Z., Jeong, M. J., Yu, H., and Zhang, Z.: CALIPSO inferred most probable heights of global dust and smoke layers, J. Geophys. Res.-Atmos., 120, 50855100, 2015.

Hennemuth, B. and Lammert, A.: Determination of the Atmospheric Boundary Layer Height from Radiosonde and Lidar Backscatter, Bound.-Lay. Meteorol. 120, 181-200, 2006.

Ho, S.-P., Peng, L., Anthes, R.A., Kuo, Y.-H., and Lin, H.-C.: Marine Boundary Layer Heights and Their Longitudinal, Diurnal, and Interseasonal Variability in the Southeastern Pacific Using COSMIC, CALIOP, and Radiosonde Data, J. Clim., 28, 28562872, 2015.

Hong, S.-Y., Noh, Y., and Dudhia, J.: A New Vertical Diffusion Package with an Explicit Treatment of Entrainment Processes, Mon. Weather Rev., 134, 2318-2341, 2006.

Jordan, N. S., Hoff, R. M., and Bacmeister, J. T.: Validation of Goddard Earth Observing System-version 5 MERRA planetary boundary layer heights using CALIPSO, J. Geophys. Res.Atmos., 115, D24218, doi:10.1029/2009jd013777, 2010.

Kim, S. W., Berthier, S., Raut, J. C., Chazette, P., Dulac, F., and Yoon, S. C.: Validation of aerosol and cloud layer structures from the space-borne lidar CALIOP using a ground-based lidar in Seoul, Korea, Atmos. Chem. Phys., 8, 3705-3720, doi:10.5194/acp-8-3705-2008, 2008

Korhonen, K., Giannakaki, E., Mielonen, T., Pfüller, A., Laakso, L., Vakkari, V., Baars, H., Engelmann, R., Beukes, J. P., Van Zyl, P. G., Ramandh, A., Ntsangwane, L., Josipovic, M., Tiitta, P., Fourie, G., Ngwana, I., Chiloane, K., and Komppula, M.: Atmospheric boundary layer top height in South Africa: measurements with lidar and radiosonde compared to three atmospheric models, Atmos. Chem. Phys., 14, 4263-4278, doi:10.5194/acp-14-42632014, 2014.

Kulmala, M., Lappalainen, H. K., Petäjä, T., Kurten, T., Kerminen, V.-M., Viisanen, Y., Hari, P., Sorvari, S., Bäck, J., Bondur, V., Kasimov, N., Kotlyakov, V., Matvienko, G., Baklanov, A., Guo, H. D., Ding, A., Hansson, H.-C., and Zilitinkevich, S.: Introduction: The Pan-Eurasian Experiment (PEEX) multidisciplinary, multiscale and multicomponent research and capacity-building initiative, Atmos. Chem. Phys., 15, 1308513096, doi:10.5194/acp-15-13085-2015, 2015. 
Leventidou, E., Zanis, P., Balis, D., Giannakaki, E., Pytharoulis, I., and Amiridis, V.: Factors affecting the comparisons of planetary boundary layer height retrievals from CALIPSO, ECMWF and radiosondes over Thessaloniki, Greece, Atmos. Environ., 74, 360-366, 2013.

Liu, J., Huang, J., Chen, B., Zhou, T., Yan, H., Jin, H., Huang, Z., and Zhang, B.: Comparisons of PBL heights derived from CALIPSO and ECMWF reanalysis data over China, J. Quant. Spectrosc. Ra., 153, 102-112, 2015.

Liu, S. and Liang, X.-Z.: Observed diurnal cycle climatology of planetary boundary layer height, J. Clim., 23, 5790-5809, 2010.

Liu, Z., Vaughan, M., Winker, D., Kittaka, C., Getzewich, B., Kuehn, R., Omar, A., Powell, K., Trepte, C., and Hostetler, C.: TheCALIPSOLidar Cloud and Aerosol Discrimination: Version 2 Algorithm and Initial Assessment of Performance, J. Atmos. Oceanic Tech., 26, 1198-1213, 2009.

McGrath-Spangler, E. L. and Denning, A. S.: Estimates of North American summertime planetary boundary layer depths derived from space-borne lidar, J. Geophys. Res.-Atmos., 117, D15101, doi:10.1029/2012JD017615, 2012.

McGrath-Spangler, E. L. and Denning, A. S.: Global seasonal variations of midday planetary boundary layer depth from CALIPSO space-borne LIDAR, J. Geophys. Res.-Atmos., 118, 1226-1233, 2013.

Medeiros, B., Hall, A., and Stevens, B.: What controls the mean depth of the PBL?, J. Clim., 18, 3157-3172, 2005.

Melfi, S., Spinhirne, J., Chou, S., and Palm, S.: Lidar observations of vertically organized convection in the planetary boundary layer over the ocean, J. Appl. Meteorol. Clim., 24, 806-821, 1985.

Miao, Y., Hu, X.-M., Liu, S., Qian, T., Xue, M., Zheng, Y., and Wang, S.: Seasonal variation of local atmospheric circulations and boundary layer structure in the Beijing-Tianjin-Hebei region and implications for air quality, J. Adv. Model. Earth Sy., 7, 125, 2015.

Miao, Y., Liu, S., Zheng, Y., and Wang, S.: Modeling the feedback between aerosol and boundary layer processes: a case study in Beijing, China, Environ. Sci. Pollut. Res., 23, 3342-3357, 2016.

Oke, T. R.: Boundary Layer Climates, 2nd Edn., Halsted Press, New York, 435 pp., 1988.

Quan, J., Gao, Y., Zhang, Q., Tie, X., Cao, J., Han, S., Meng, J., Chen, P., and Zhao, D.: Evolution of planetary boundary layer under different weather conditions, and its impact on aerosol concentrations, Particuology, 11, 34-40, 2013.

Sawyer, V. and Li, Z.: Detection, variations and intercomparison of the planetary boundary layer depth from radiosonde, lidar and infrared spectrometer, Atmos. Environ., 79, 518-528, 2013.

Seibert, P.: Review and intercomparison of operational methods for the determination of the mixing height, Atmos. Environ., 34, 1001-1027, 2000.

Seidel, D. J., Ao, C. O., and Li, K.:, Estimating climatological planetary boundary layer heights from radiosonde observations: Comparison of methods and uncertainty analysis, J. Geophys. Res.-Atmos., 115, D16113, doi:10.1029/2006JD008337, 2010.

Seidel, D. J., Zhang, Y., Beljaars, A., Golaz, J.-C., Jacobson, A. R., and Medeiros, B.: Climatology of the planetary boundary layer over the continental United States and Europe, J. Geophys. Res.Atmos., 117, D17106, doi:10.1029/2012JD018143, 2012.
Sorbjan, Z.: Structure of the Atmospheric Boundary Layer, Prentice Hall, Englewood Cliffs, NJ, 317 pp., 1989.

Steyn, D. G., Baldi, M., and Hoff, R. M.: The detection of mixed layer depth and entrainment zone thickness from lidar backscatter profiles, J. Atmos. Oceanic Tech., 16, 953-959, 1999.

Stull, R. B.: An introduction to boundary layer meteorology, Springer Science \& Business Media, 1988.

Torres, O., Bhartia, P. K., Herman, J. R., Ahmad, Z., and Gleason, J.: Derivation of aerosol properties from satellite measurements of backscattered ultraviolet radiation: Theoretical basis, J. Geophys. Res.-Atmos., 103, 17099-17110, 1998.

Torres, O., Ahn, C., and Chen, Z.: Improvements to the OMI nearUV aerosol algorithm using A-train CALIOP and AIRS observations, Atmos. Meas. Tech., 6, 3257-3270, doi:10.5194/amt-63257-2013, 2013.

Wang, F., Guo, J., Zhang, J., Huang, J., Min, M., Chen, T., Liu, H., Deng, M., and Li, X.: Multi-sensor quantification of aerosolinduced variability in warm cloud properties over eastern China, Atmos. Environ., 113, 1-9, 2015.

Wang, Y., Wan, Q., Meng, W., Liao, F., Tan, H., and Zhang, R.: Long-term impacts of aerosols on precipitation and lightning over the Pearl River Delta megacity area in China, Atmos. Chem. Phys., 11, 12421-12436, doi:10.5194/acp-11-12421-2011, 2011.

Wang, Y., Khalizov, A., Levy, M., and Zhang, R., New Directions: Light Absorbing Aerosols and Their Atmospheric Impacts, Atmos. Environ., 81, 713-715, 2013a.

Wang, Y., Fan, J., Zhang, R., Leung, R., and Franklin, C., Improving Bulk Microphysics Parameterizations in Simulations of Aerosol Indirect Effects, J. Geophys. Res.-Atmos., 118, 53615379, 2013 b.

Winker, D. M., Pelon, J. R., and McCormick, M. P.: The CALIPSO mission: Spaceborne lidar for observation of aerosols and clouds, Third International Asia-Pacific Environmental Remote Sensing Remote Sensing of the Atmosphere, Ocean, Environment, and Space, International Society for Optics and Photonics, 1-11, 2003.

Winker, D. M., Hunt, W. H., and McGill, M. J.: Initial performance assessment of CALIOP, Geophys. Res. Lett., 34, L19803, doi:10.1029/2007GL030135, 2007.

Winker, D. M., Vaughan, M. A., Omar, A., Hu, Y., Powell, K. A., Liu, Z., Hunt, W. H., and Young, S. A.: Overview of the CALIPSO Mission and CALIOP Data Processing Algorithms, J. Atmos. Oceanic Tech., 26, 2310-2323, 2009.

Xia, X., Li, Z., Wang, P., Chen, H., and Cribb, M.: Estimation of aerosol effects on surface irradiance based on measurements and radiative transfer model simulations in northern China, J. Geophys. Res.-Atmos., 112, D22S10, doi:10.1029/2011JD017080, 2007.

Xie, B., Fung, J. C. H., Chan, A., and Lau, A.: Evaluation of nonlocal and local planetary boundary layer schemes in the WRF model, J. Geophys. Res.-Atmos., 117, D12103, doi:10.1029/ 2009JD013680, 2012.

Yang, X., Zhao C., Guo J., and Wang Y.: intensification of air pollution associated with its feedback with surface solar radiation and winds in Beijing, J. Geophys. Res.-Atmos., 121, 4093-4099, 2016.

Zhang, F., Bei, N., Nielsen-Gammon, J. W., Li, G., Zhang, R., Stuart, A., and Aksoy, A.: Impacts of meteorological uncertainties on ozone pollution predictability estimated through meteo- ro- 
logical and photochemical ensemble forecasts, J. Geophys. Res.Atmos., 112, D04304, doi:10.1029/2006JD007429, 2007.

Zhang, R., Wang, G., Guo, S., Zamora, M., Lin, Y., Wang, W., Hu, M., and Wang, Y.: Formation of Urban Fine Particulate Matter, Chem. Rev., 115, 3803-3855, 2015.
Zhang, W., Augustin, M., Zhang, Y., Li, Z., Xu, H., Liu, D., Wang, Z., Zhang, Y., Ma, Y., and Zhang, F.: Spatial and Temporal Variability of Aerosol Vertical Distribution Based on Lidar Observations: A Haze Case Study over Jinhua Basin, Adv. Meteorol. 2015, 349592, doi:10.1155/2015/349592, 2015. 